\title{
Relationship between Attachment Styles to Somatization and Anxiety
}

\author{
Shima Pajouhinia ${ }^{*}$, Reza Faraji², Seyed Mohammad Hasan Fatemi Ardestani ${ }^{3}$ \\ ${ }^{1}$ Psychology Department, Education and Psychology Faculty, Allameh Tabatabaei University, Tehran, Iran. \\ ${ }^{2}$ Psychology Department, Education and Psychology Faculty, Payam-e Noor University, Tehran, Iran. \\ ${ }^{3}$ Department of Qur'an and Hadith Sciences, Usul Al Deen College, Tehran, Iran.
}

\section{ABSTRACT}

Introduction: Attachment theory is one of the appropriate models for understanding the adaptive and maladaptive methods that people are faced multiple developmental challenges by these models. Secure attachment Experience is necessary for healthy and normal development, and it is the substructure of mental health functioning. This study examined the relationship between attachment styles with anxiety and somatization disorders. Materials and Methods: The research was a descriptive-correlational study. The statistical population comprised of all students at coed universities in Tehran. A group of 384 male and female students (due to the population size by using the Cochran formula), using random multiple cluster sampling method, were selected. The adult attachment inventory (AAI) and the symptom checklist-90-revised (SCL-90-R) were completed by these students. For data analysis, correlation coefficients and regression analysis were used. Results: Our data revealed a significant correlation between attachment style and vulnerability to anxiety and somatization disorders. Conclusion: Insecure attachment styles (ambivalent and avoidant) can play an important role in the creation and maintenance of anxiety and somatization disorders. Therefore, evaluation of these traumatic factors can lead to a new orientation in the prevention, diagnosis, and treatment of the disorders mentioned above.

\section{Key words:}

1. Somatoform Disorders

2. Anxiety

3. Psychology

* Corresponding Author: Shima Pajouhinia

E-mail:sh.pajouhinia@yahoo.com 


\title{
بررسى رابطة بين سبكهاى دلبستخى با جسمانىسازى و اضطراب
}

\author{
شيما يزوهى نيا'"، رضا فرجى '، سيد محمد حسن فاطمى اردستانى \\ ' كروه روانشناسى، دانشكده علوم تربيتى و روانشناسى، دانشكاه علامه طباطبائى، تهران، ايران.

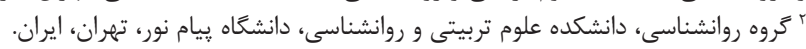

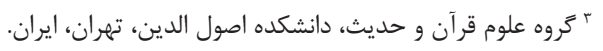

كليد وازهها:

إ. اختلالات شبه جسمانى

r.

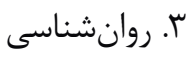

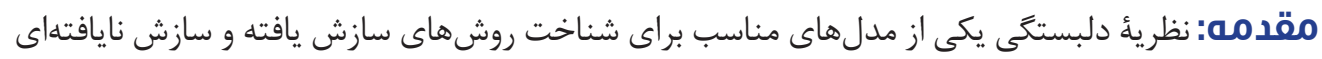

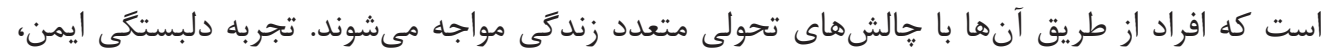

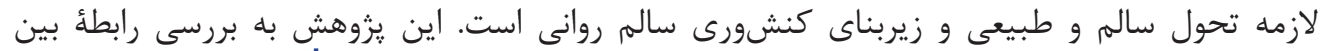

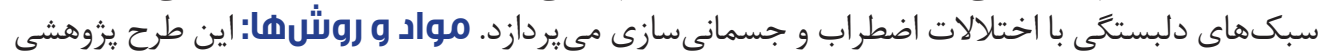

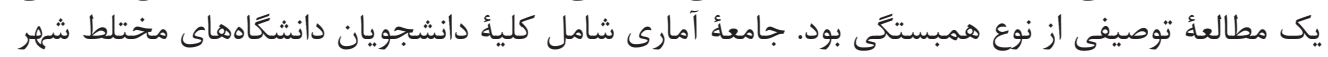

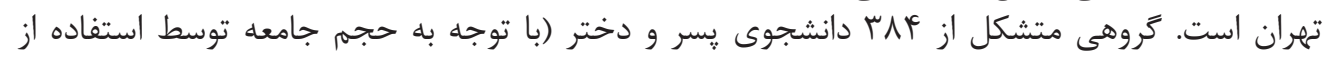

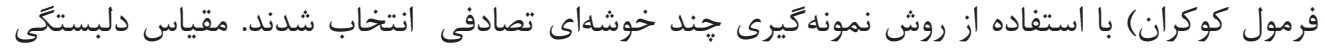

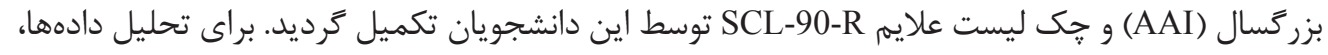

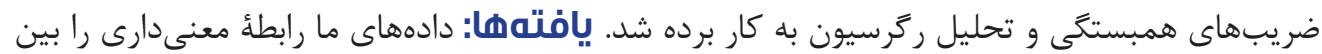

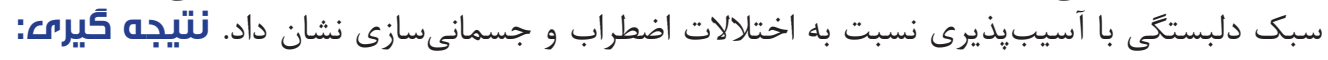

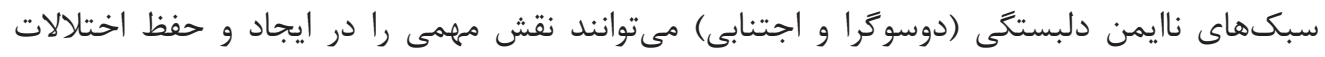

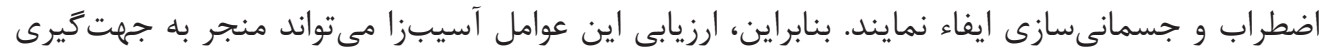

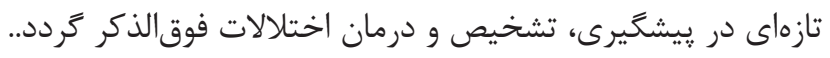

" نويسنده مسئول: شيما بزوهى نيا آدرس الكترونيكى: sh.pajouhinia@yahoo.com 


\section{كم ارزش و با تأثير اندك ارزيابى مى كنند ( • ، 9).}

افراد داراى سبك دلبستخى دوسوگرا، اغلب از اينكه ديخران

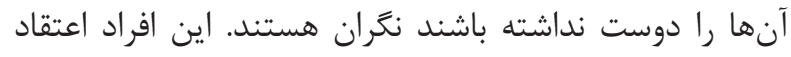

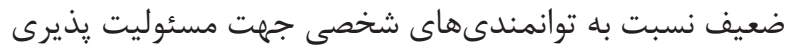

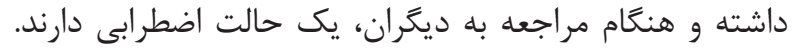

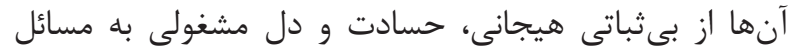

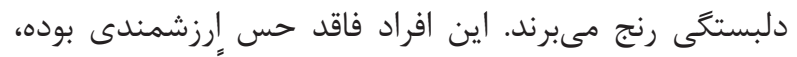

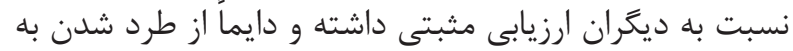

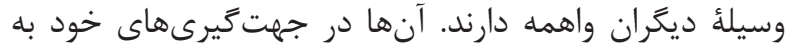

شدت تابع جهت گيرىهاى بيرونى هستند (9) (9).

يزوهشهاى متعدد، رابطة بين دلبستتى و آسيبشناسى روانى

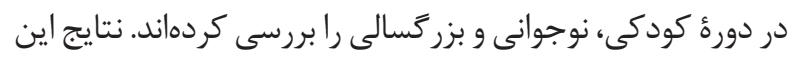

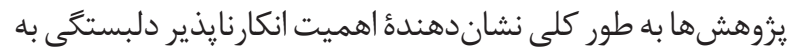

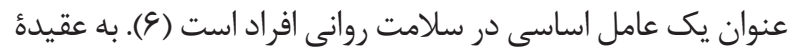

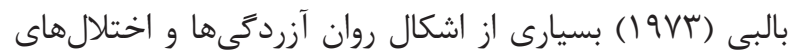

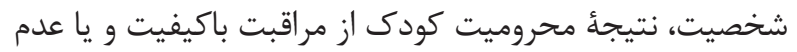

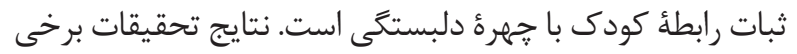

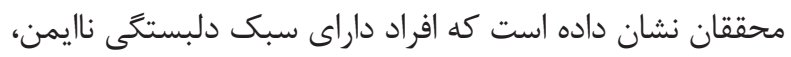

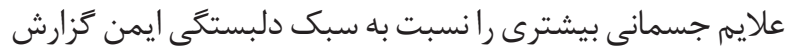

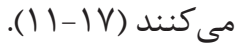

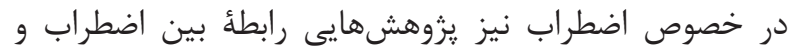

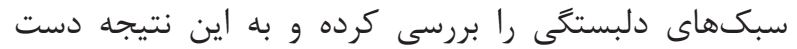
يافتند كه افرادى كه داراى دلبستيتى دلى ايمن بورئ بوده، اضطراب

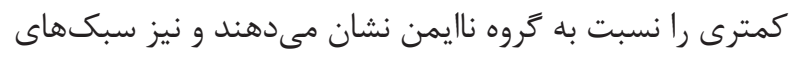

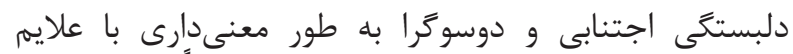

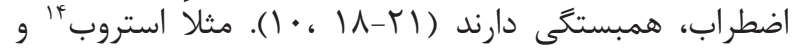

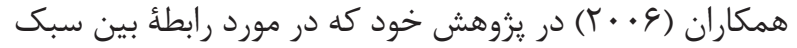

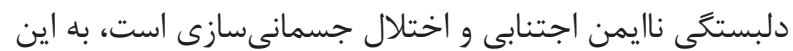

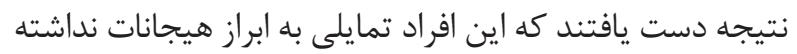

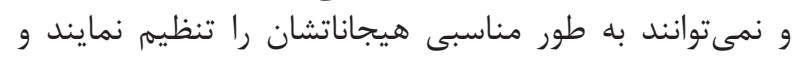

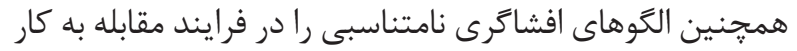

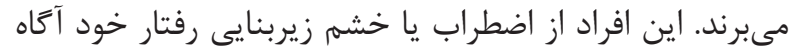

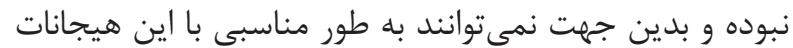

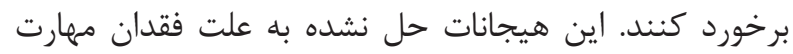

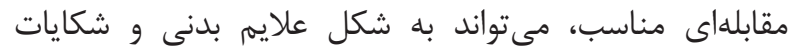

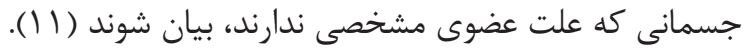

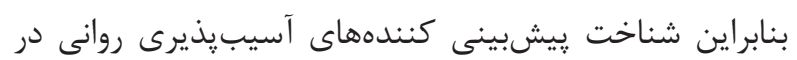

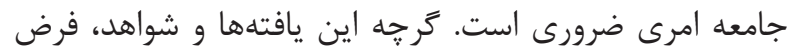

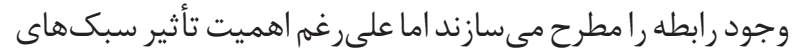

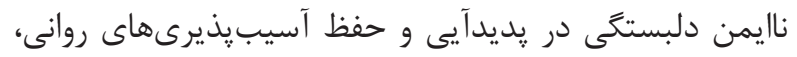

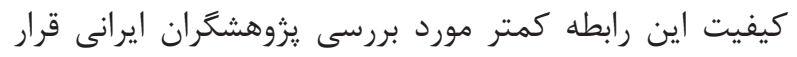

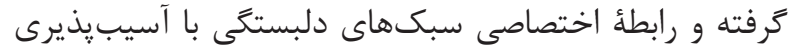

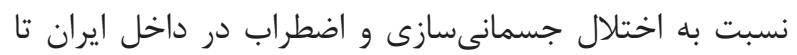

${ }^{1}$ Diathesis-stress model

${ }^{2}$ Bowlby

${ }^{3}$ Attachment

${ }^{4}$ Secure attachment style

${ }^{5}$ Avoidant

${ }^{6}$ Ambivalent

${ }^{7}$ Sensitivity
يزوهشهاى زيادى براساس مدل آسيبيذيرى -استرس' در

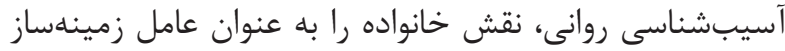

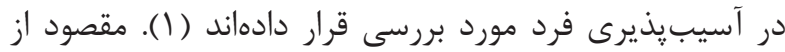

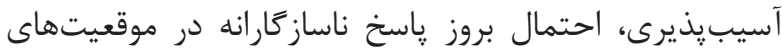

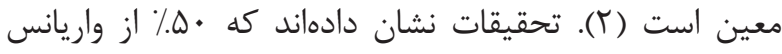

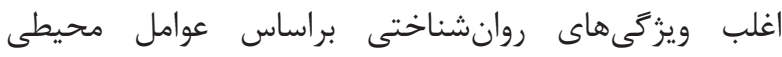

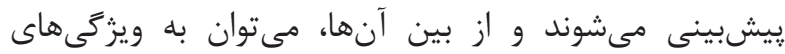

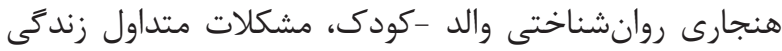

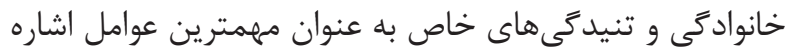

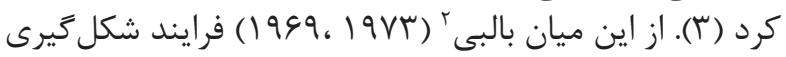

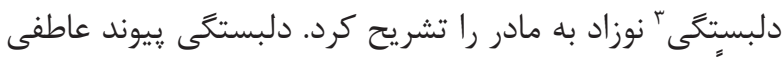

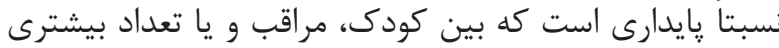

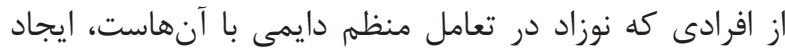

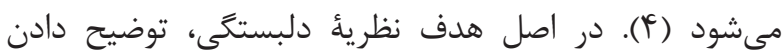

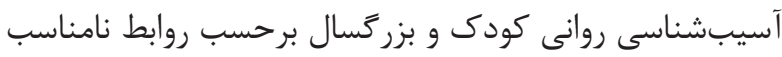

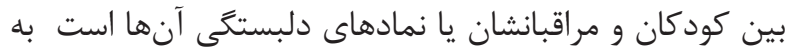

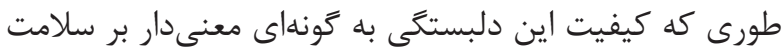

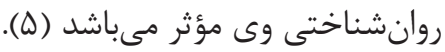

به دنبال يزوهش هاى بالبى، اينسورث و همكاران (19VA) سه

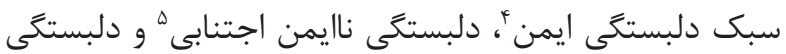

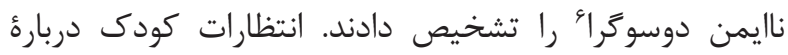

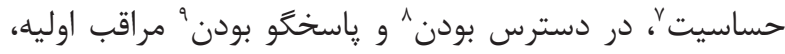

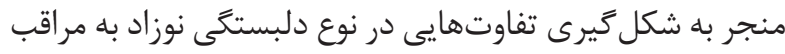

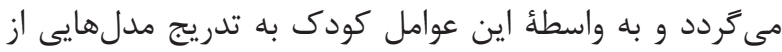

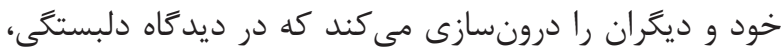

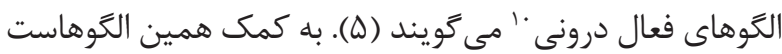

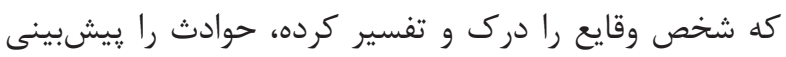

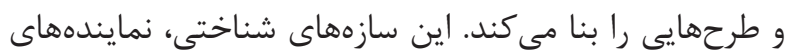

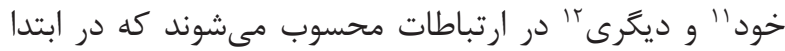

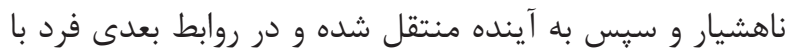

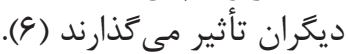

بزر گسالان با سبك دلبستخى ايمن، افرادى هستند كه به آسانى

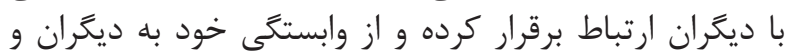

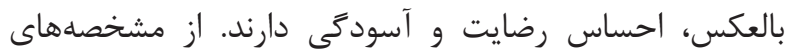

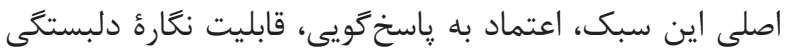

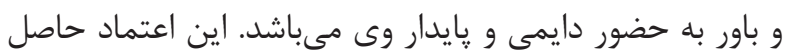

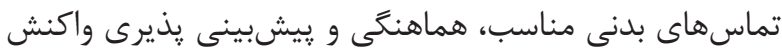
نعاره دلبستخى در برخورد با كودى است (V) ، (V).

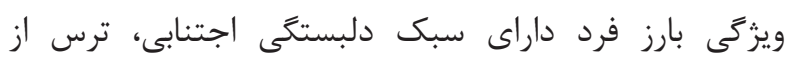

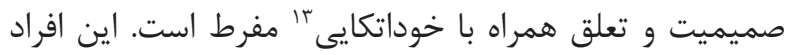

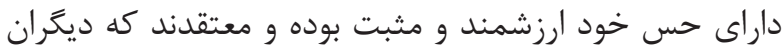

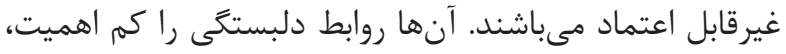

\footnotetext{
${ }^{8}$ Accessibility

${ }^{9}$ Responsiveness

${ }^{10}$ Internal working models

${ }^{11}$ Model of self

${ }^{12}$ Model of others

${ }^{13}$ Self- reliant

${ }^{14}$ Stroebe
} 
دلبستخى دوسو

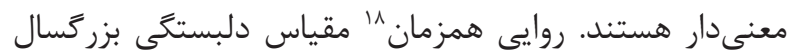

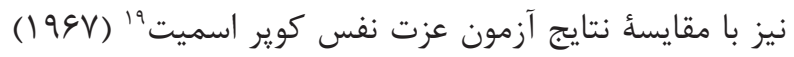
بررسى شد.

ضرايب همبستخى بين نمره كلى آزمودنىها در آزمون عزت

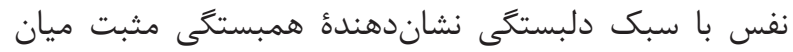

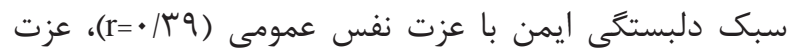

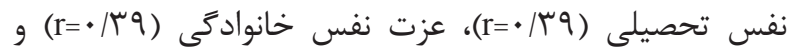

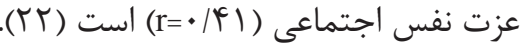

\section{جك ليست علايم SCL-90-R}

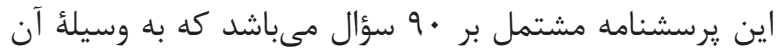

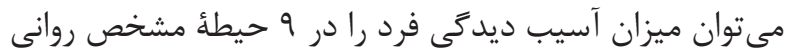

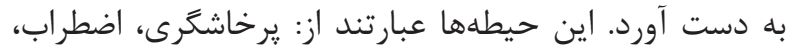

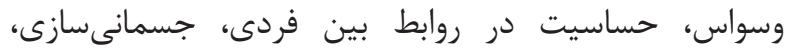

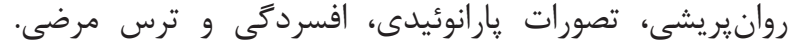

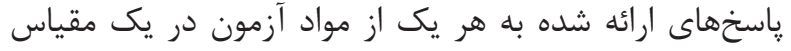

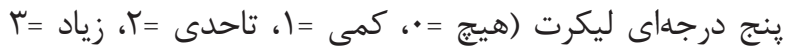

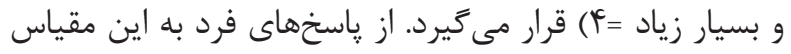

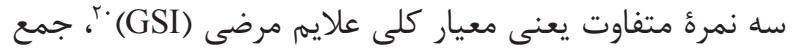

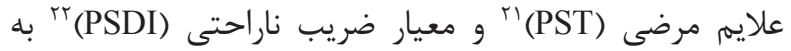

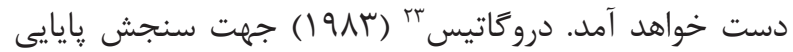

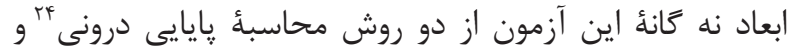

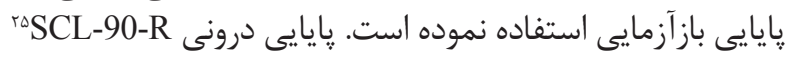

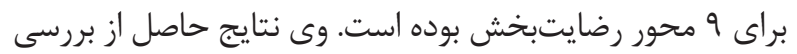

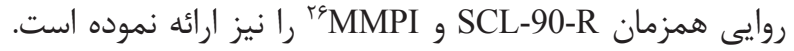

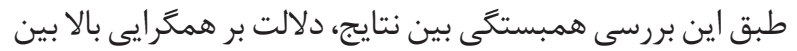

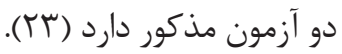

دادههاى جمع آورى شده از طريق ضريب همبستتى يیيرسون و

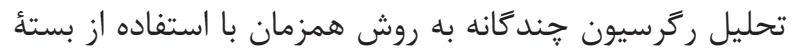

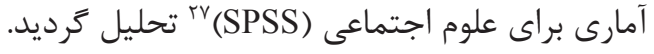

يافته ها

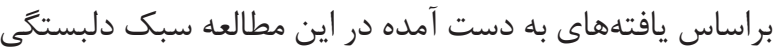

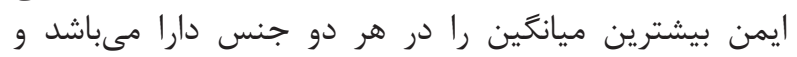

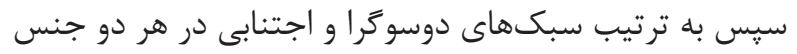

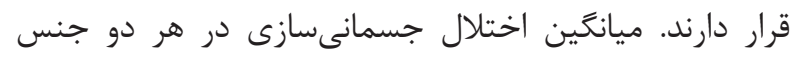

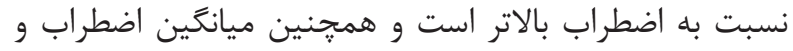

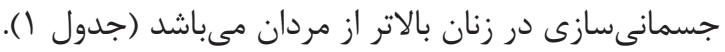
براى بررسى رابطة بين آسيب ڤيذيرى نسبت به جسمانىسازى و

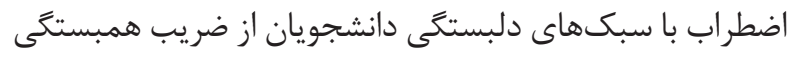

\footnotetext{
${ }^{15}$ Adult attachment inventory (AAI)

${ }^{16}$ Hazan and Shaver

${ }^{17}$ Content validity

${ }^{18}$ Concurrent validity

${ }^{19}$ Coppersmith Self-Esteem Inventory

${ }^{20}$ Global severity index (GSI)

${ }^{21}$ Positive symptom test (PST)
}

كنون بررسى نشده است. مطالعات و يزوهشهاى ييشين بيشتر

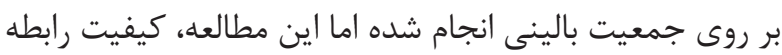

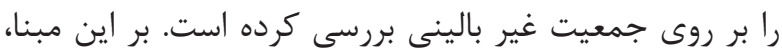

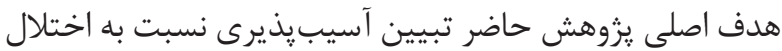

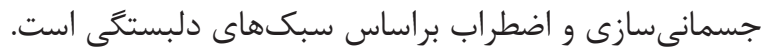

مواد و روشها - ماد روش يزوهش، جامعلة آمارى و نمونه

طرح يزوهشى حاضر، در زمره طرحهاى توصيفى از نوع

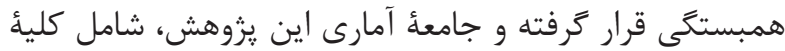

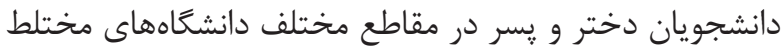

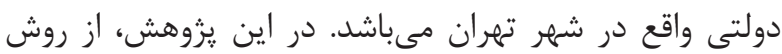
نمونه

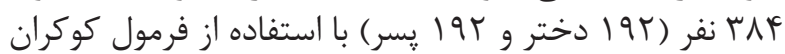
به دست آمده است.

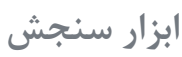

\section{مقياس دلبستخَى بزركسال}

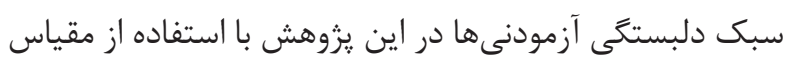
دلبستخى بزر كسال (AAI)

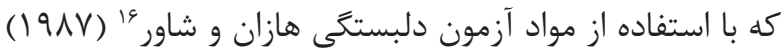

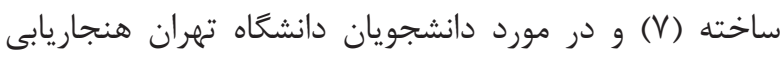

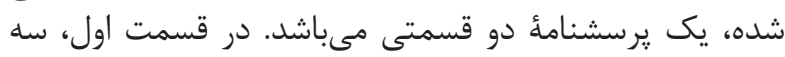

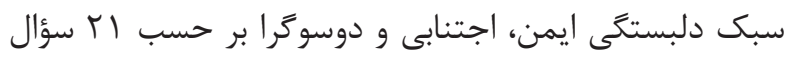

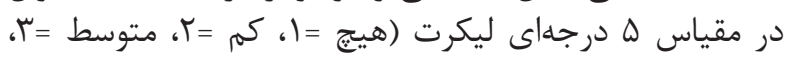

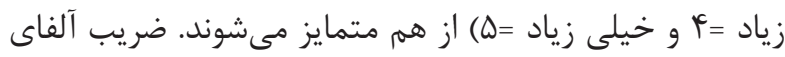

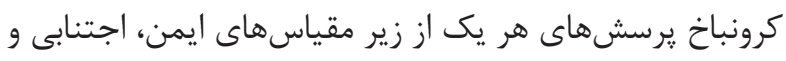
دوسو

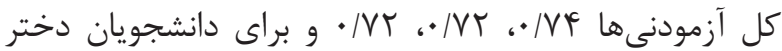

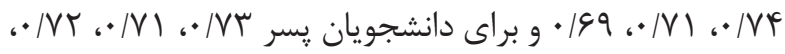

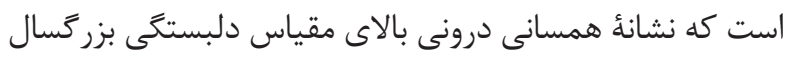

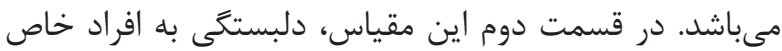

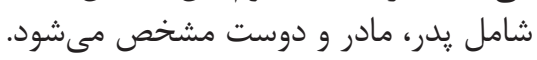

در اين يروهش از قسمت نخست آن براى تعيين سبك دلبستكى

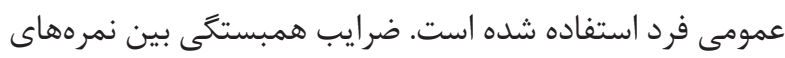

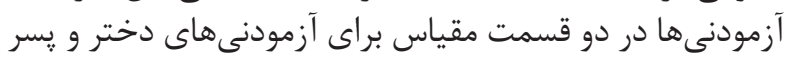

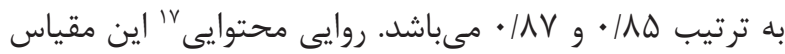

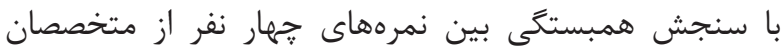

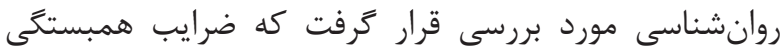

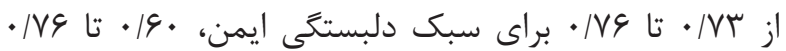

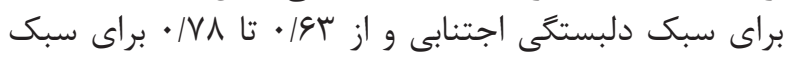

\footnotetext{
${ }^{22}$ Positive symptom distress index (PSDI)

${ }^{23}$ Derogatis

${ }^{24}$ Internal reliability

${ }^{25}$ Symptom checklist-90-revised (SCL-90-R)

${ }^{26}$ Minnesota multiphase personality inventory (MMPI)

${ }^{27}$ Statistical package for social science (SPSS)
} 
جدول ا- دادههاى توصيفى مربوط به نمر ههاى كروه نمونه در ابعاد مورد بررسى به تفكيك جنسيت

\begin{tabular}{|c|c|c|c|}
\hline انحراف معيار & ميانين & جنسيت & متغير ها \\
\hline$V / 9 T$ & $q / T G$ & زن & \multirow{3}{*}{ اضطراب } \\
\hline $9 / 19$ & $N / F T$ & مرد & \\
\hline$V / F T$ & $\Lambda / \Lambda \Delta$ & كل & \\
\hline $9 / 9)$ & $11 / 49$ & زن & \multirow{3}{*}{ جسمانى سازى } \\
\hline $1 / \Delta)$ & $1 \cdot 1 \cdot V$ & 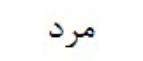 & \\
\hline$q / T \Delta$ & $1 \cdot / \mathrm{VA}$ & كل & \\
\hline ( - & $|f / F|$ & زن & \multirow{3}{*}{ دلبستخَى ايمن } \\
\hline$r / \Delta F$ & $10 / N$ & 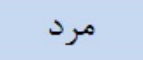 & \\
\hline$r / F V$ & $1 F / V F$ & كل & \\
\hline$\Gamma / T \Delta$ & $|T / V|$ & زن & \multirow{3}{*}{ دلبستخى اجتنابى } \\
\hline 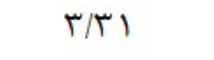 & $1 T / 90$ & 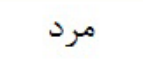 & \\
\hline r/r人 & IT/DT & كل - كل & \\
\hline r/Fr & IT/TF & زن & \multirow{3}{*}{ دلبستخى دوسوترا } \\
\hline r/GF & $\mid \pi / F \wedge$ & 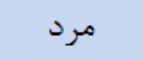 & \\
\hline$r / \Delta T$ & $|\pi / 4|$ & كل & \\
\hline
\end{tabular}

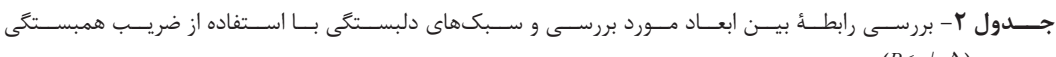

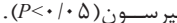

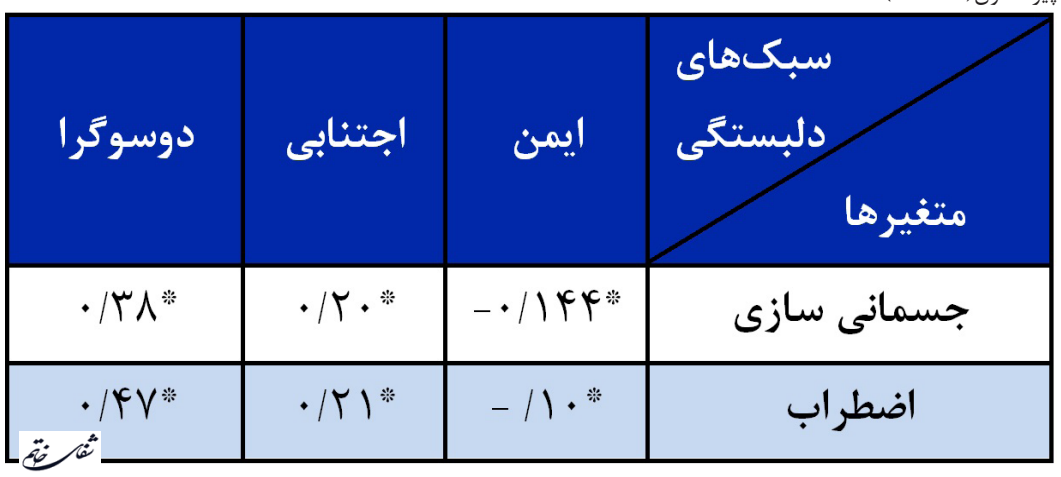

(جهار متغيرى) براى تركيب خطى سبكهاى دلبستكى ايمن،

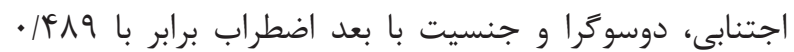

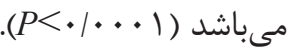

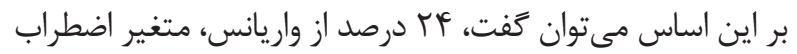

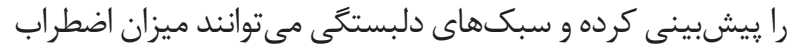

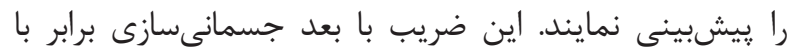

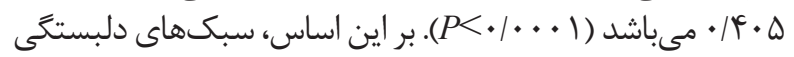

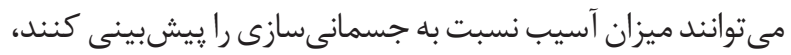

يِيرسون استفاده شده است. نتايج جدول r نشان مى إدهد، بين

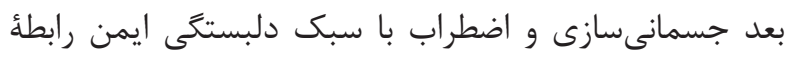

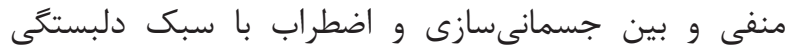
اجتنابى و دوسو مرا رابطؤ مثبت معنى دار وجود دارد.

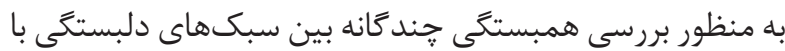

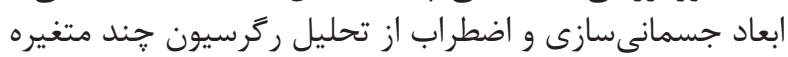

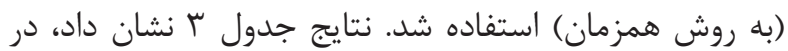

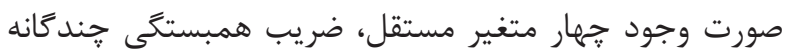




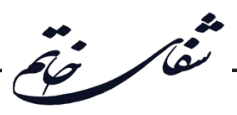

جدول بـ- نتايج تحليل رگرسيون جندگًانه سبكهاى دلبستگى و جنسيت با ابعاد اضطراب و جسمانى سازى با روش همزمان.

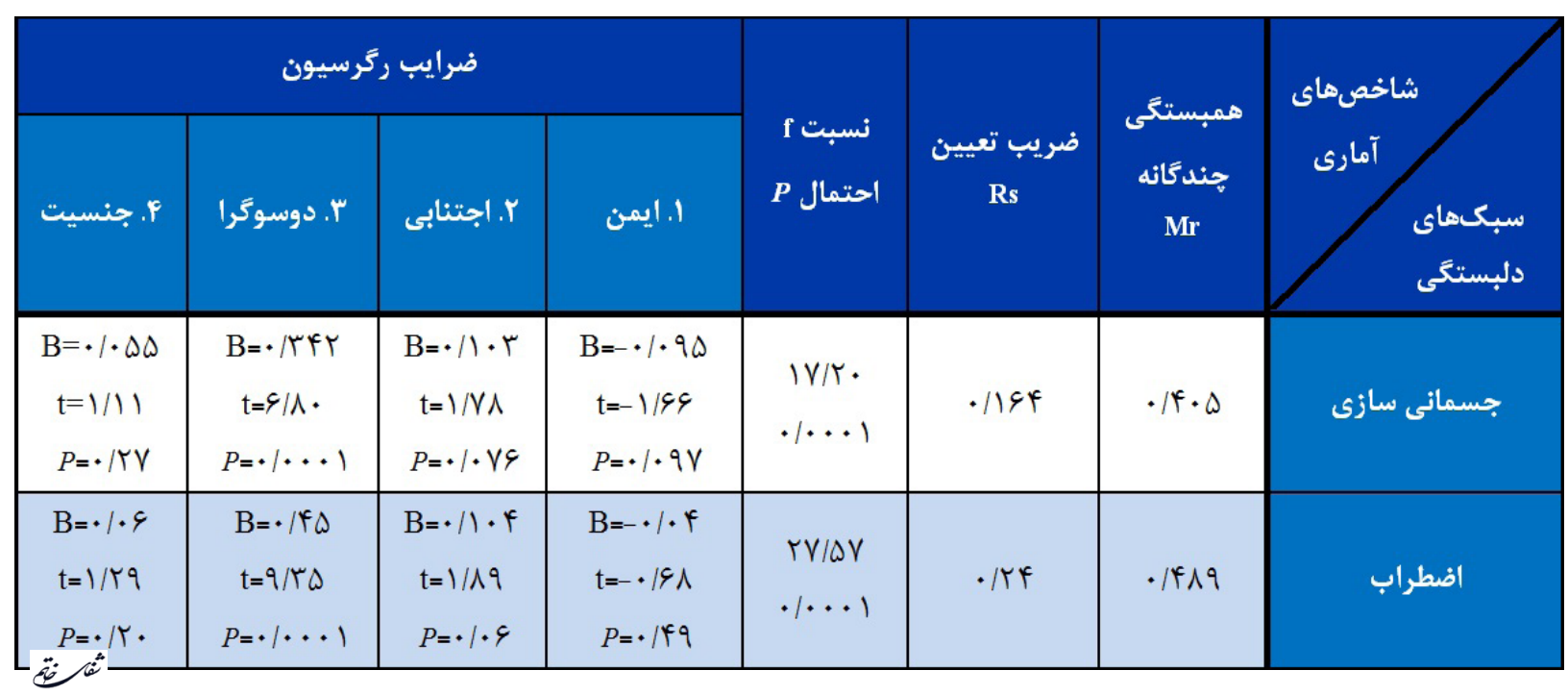

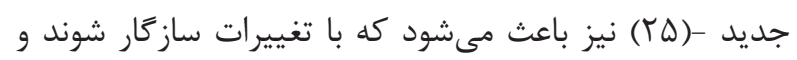

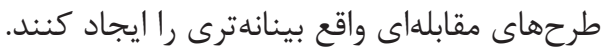

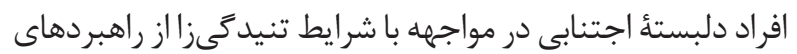

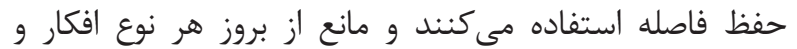

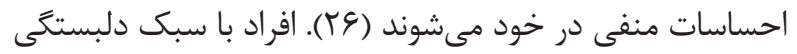

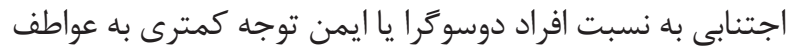

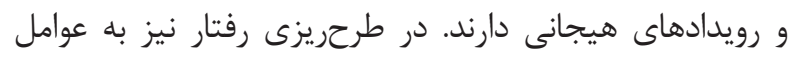

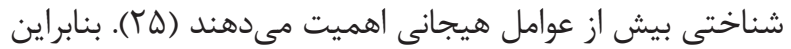

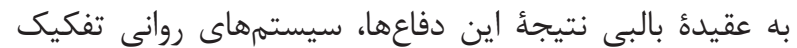

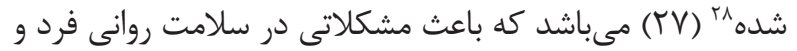

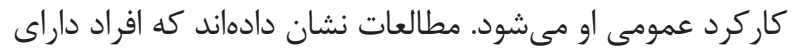

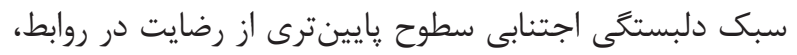

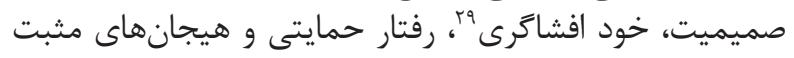

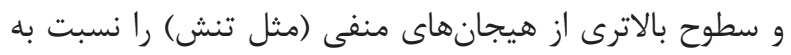

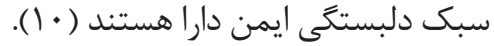

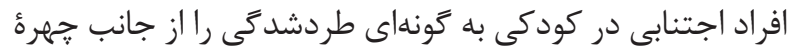

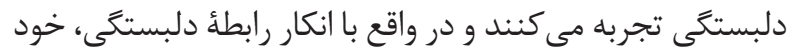

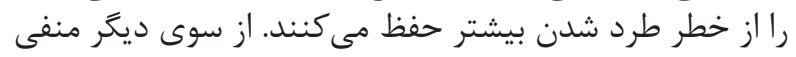

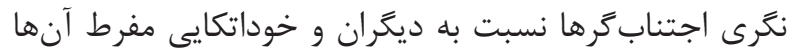

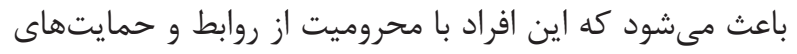

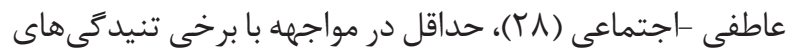

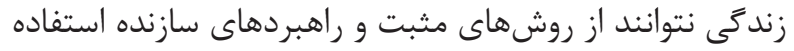

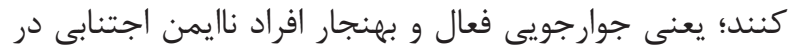

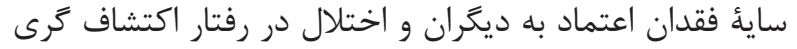

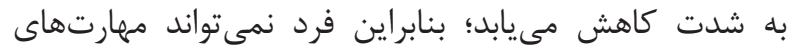

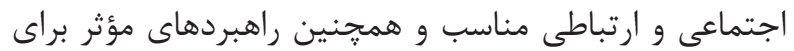

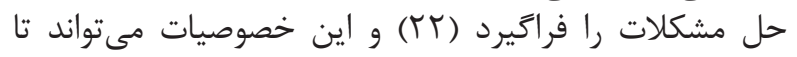

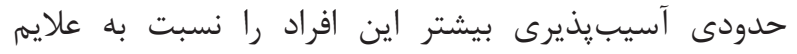

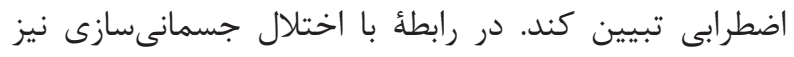

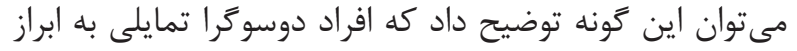

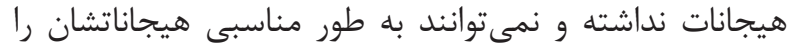

زيرا 1 ا درصد از واريانس جسمانىسازى را يِيشبينى مى كنند.

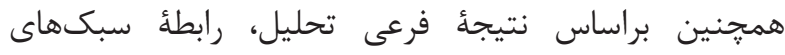

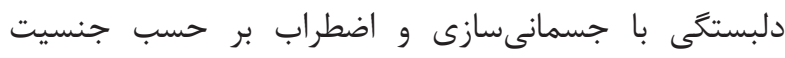

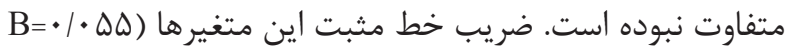

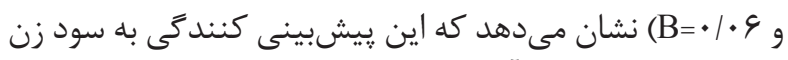

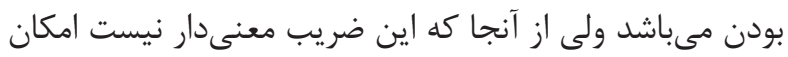

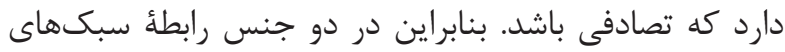

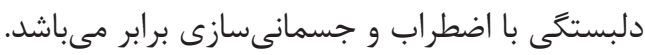

$$
\text { بحث و نتيجه كيرى }
$$

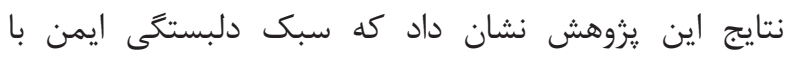

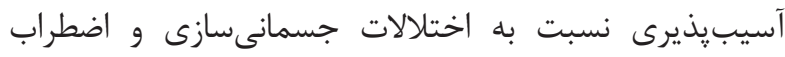

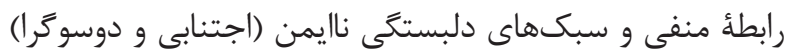

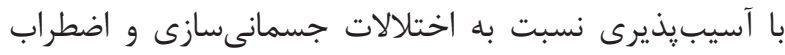

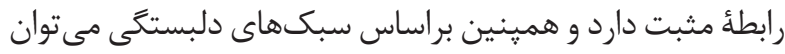

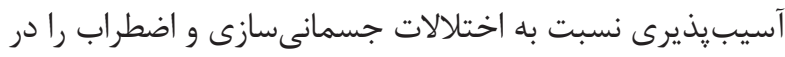

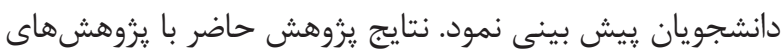

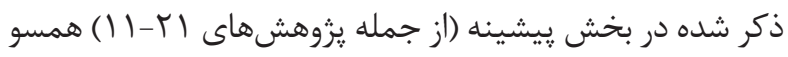

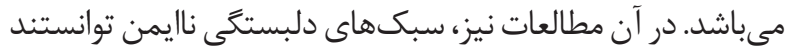
اختلال جسمانى سازى و اضطراب را ريش بيش بينى كنند.

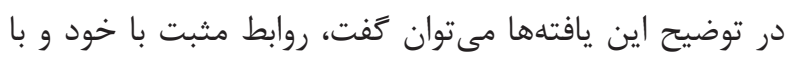

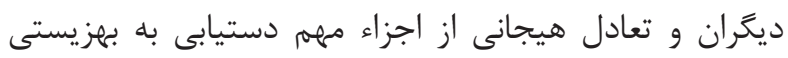

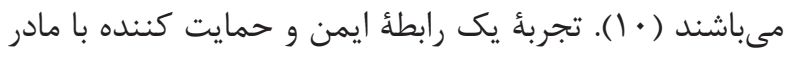

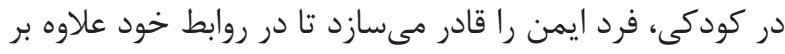

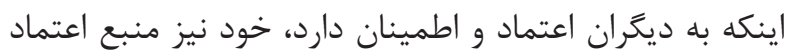

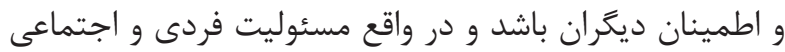

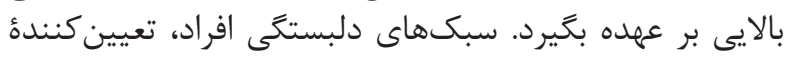

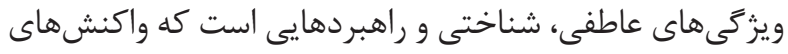

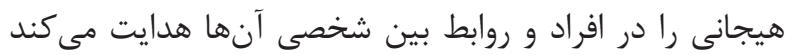

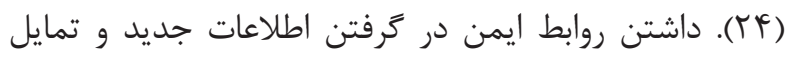

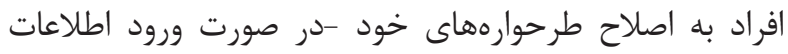

\footnotetext{
${ }^{28}$ Segregated mental systems

${ }^{29}$ Self-disclosure
} 
است كه در آن فرد به طور مناسبى قادر به حل و بازگشايى آنسي

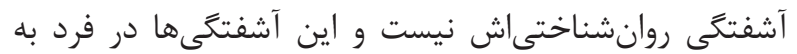
صورت علايم بدنى ظهور مى يابند (1) آن.

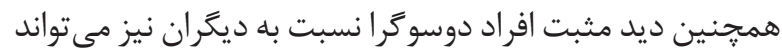

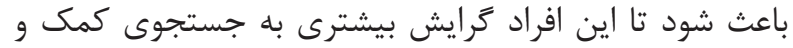

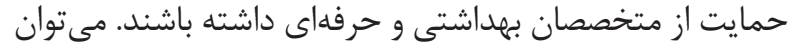

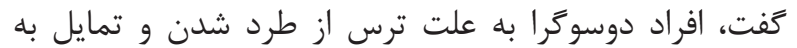

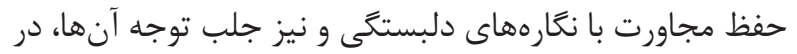

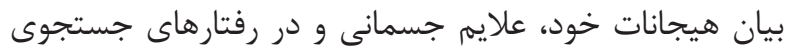
حمايت و مراقبت اغراق مى كنند (T) (r).

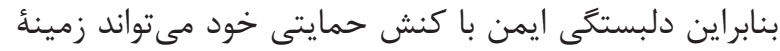

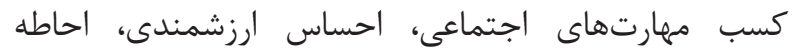

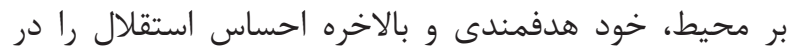

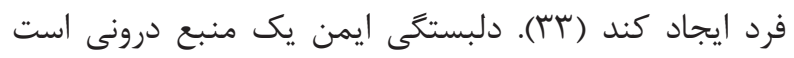

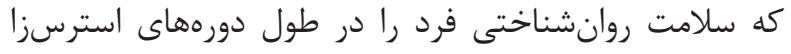

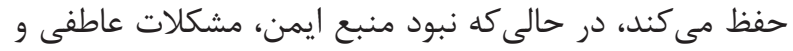

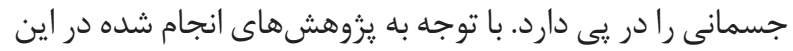

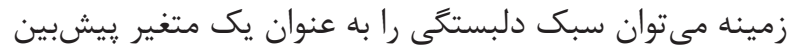

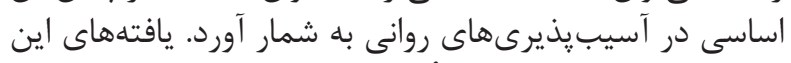

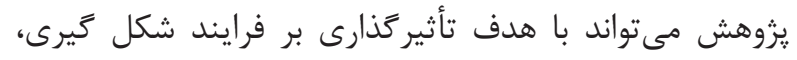

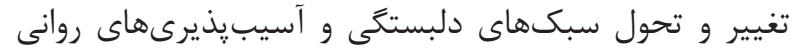

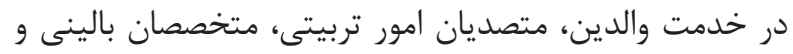

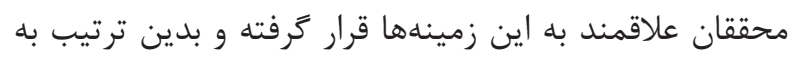

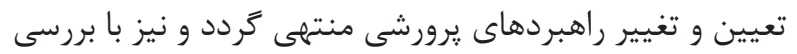

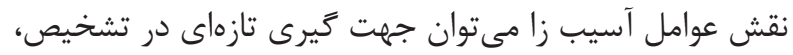

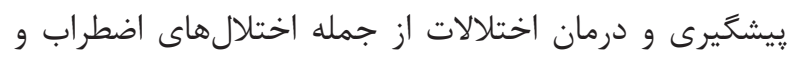
جسمانىسازى به وجود آورد.

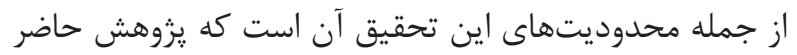

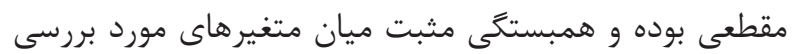

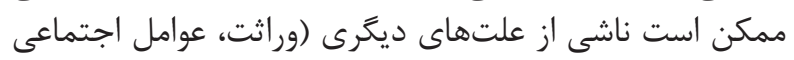

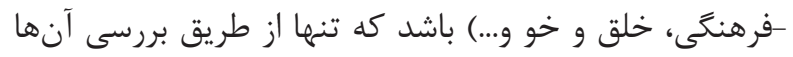

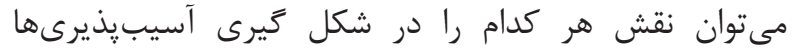

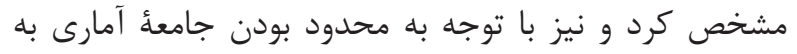

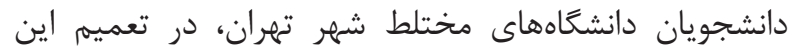

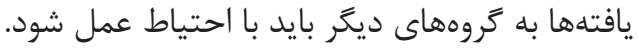

1. Harris AE, Curtin L. Parental perception, Early Maladaptive schemas and Depressive symptoms in young adult. Cognit Ther Res. (2002); 26(3): 405-16.

2. Garmezy N. Stressors of childhood. Garmezy N, Rutter M. Stress, coping and development in children. New York: McGraw-Hill. 1983; p. 43-84.

3. Rutter M. Resilience concepts and findings:
تنظيم كنند و الكَوهاى افشاكرى نامتناسبى را در فرايند مقابله

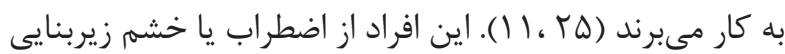

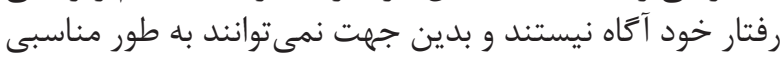

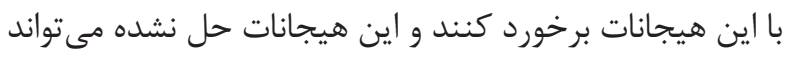

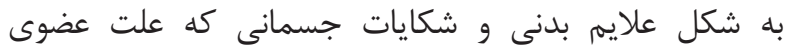

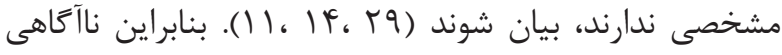

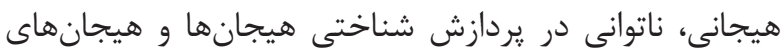

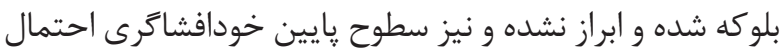

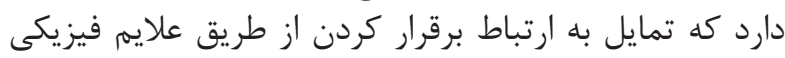

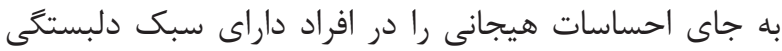

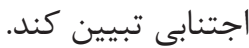

افراد دلبستهٔ دوسوكرا نيز از راهبردهاى متمركز بر هيجاني،

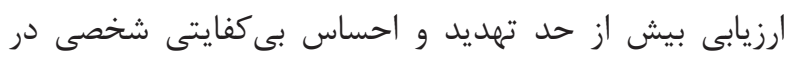

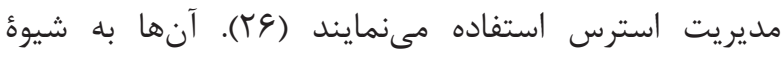

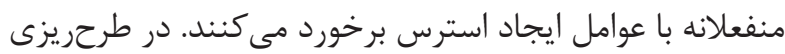

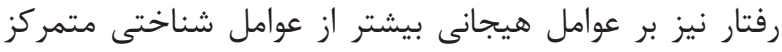

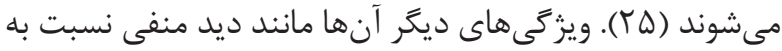

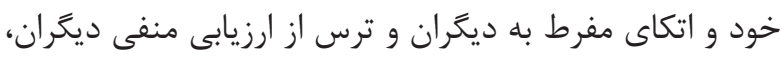

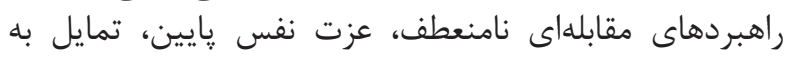

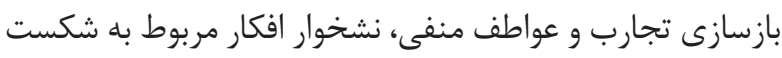

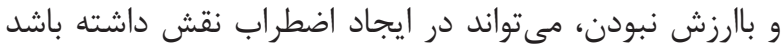

بنابراين فقدان اعتماد به خود با تحليل بنيادهاى درون روانى،

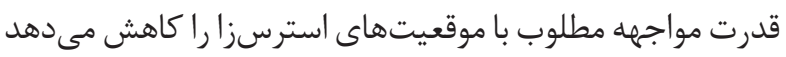

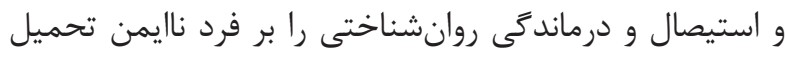

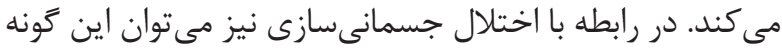

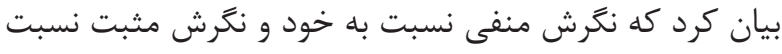

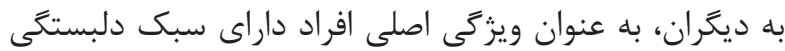

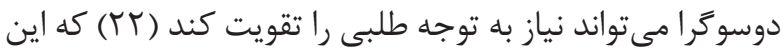

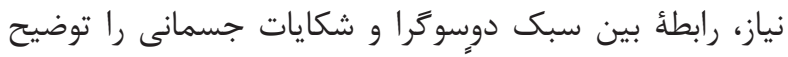

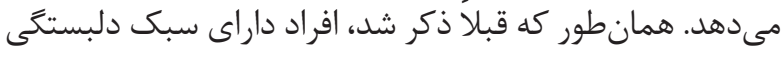

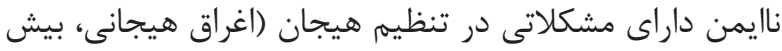

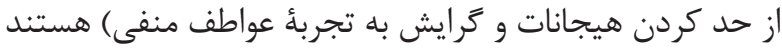

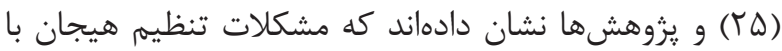

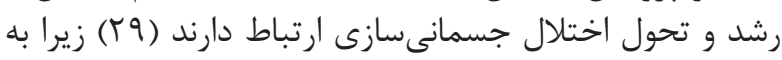

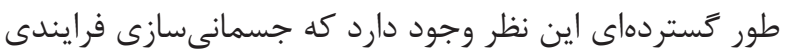

منابع

Implications for family therapy. J Fam Ther. 1999; 21: 119-44.

4. Bowlby J. Separation, anxiety and anger. $2^{\text {nd }}$ ed. New York: Basic Books. 1973.

5. Van den Dries L, Juffer F, Van Ijzendoorn $\mathrm{MH}$, Bakermans-Kranenburg MJ. Fostering security? A meta-analysis of attachment in adopted children. Child Youth Serv Rev. 2009; 31: 410-21. 
6. Morley TE, Moran G. The origins of cognitive vulnerability in early childhood: Mechanisms linking early attachment to later depression. Clin Psychol Rev. 2011; 31(7): 1071-82.

7. Hazan C, Shaver P. Romantic love conceptualized as an attachment process. J Pers Soc Psychol. 1987; 52: 511-24.

8. Brumariu LE, Kerns KA. Mother-child attachment and social anxiety symptoms in middle childhood. $\mathrm{J}$ Appl Dev Psychol. 2008; 29(5): 393-402.

9. Lyddon WJ, Sherry A. Developmental personality styles: An attachment theory conceptualization of personality disorders. J Couns Dev. 2001; 79: 405-15.

10. Priceputu M. Attachment style-from theory to the integrative intervention in anxious and depressive symptomathology. Procedia Soc Behav Sci. 2012; 33: 934-8.

11. Stroebe M, Folkman S, Hansson R, Schut H. The prediction of bereavement outcome: Development of an integrative risk factor framework. Soc Sci Med. 2006; 63(9): 2440-51.

12. Taylor RE, Mann AH, White NJ, Goldberg DP. Attachment style in patients with unexplained physical complaints. Psychol Med. 2000; 30(4): 931-41.

13. Ciechanowski P, Sullivan M, Jensen M, Romano J, Summers H. The relationship of attachment style to depression, catastrophizing and health care utilization in patients with chronic pain. Pain. 2003; 104: 627-37.

14. Weardon AJ, Cook L, Vaughan-Jones J. Adult attachment, alexithymia, symptom reporting, and healthrelated coping. J Psychosom Res. 2003; 55: 341-7.

15. Wayment HA, Vierthaler J. Attachment style and bereavement reactions. J Loss Trauma. 2002; 7: 129-49.

16. Ciechanowski PS, Waker EA, Katon WL, Russo JE. Attachment theory; a model for health care utilization and somatization. Psychol Med. 2002; 64: 660-7.

17. Waldinger RJ, Mars SS, Arthur J, Barsky J, David KP. Mapping the road From Childhood Trauma to Somatization: The Role of Attachment. Psychol Med. 2006; 68: 129- 35 .

18. Manassis K, Bradley S, Goldberg S, Hood J, Swenson RP. Attachment in mothers with anxiety disorders and their children. J Am Acad Child Adolesc Psychiatry. 1994; 33: 1106-13.

19. Muris P, Meesters C, Melick M, Zwambag L. Self-reported attachment style, attachment quality and symptoms of anxiety and depression in young adolescents. Pers Individ Dif. 2001; 30: 809-18.

20. Mitchell SH, Doumas D. The relationship between adult attachment style and depression, anxiety, and selfesteem. Presented at the Rocky Mountain Psychological Association Annual Conference. Retrieved July 24, 2008, from http://familystudies.boi-sestate.edu/pdf/Doumas2. pdf. 2004; 16: 39-52.

21. Brown AM, Whiteside SP. Relations among perceived parental rearing behaviors, attachment style, and worry in anxious children. J Anxiety Disord. 2008; 22: $263-72$.

22. Besharat MA. Finding a criteria for normal attachment in adults. Research Report. Tehran University. Iran. 2000.

23. Derogatis LR. SCL-90-R administration, scoring, and procedures. $2^{\text {nd }}$ ed. Manual II. Towson, MD: Clinical Psychometric Research. 1983.

24. Collins NL. Working models of Attachment: Implication for explanation, emotion and behavior. J Pers Soc Psychol. 1996; 74(5): 1380-97.

25. Lang A. Attachment and emotion regulation- clinical implications of a non-clinical sample study. Procedia Soc Behav Sci. 2010; 5: 674-8.

26. Mikulincer M, Horesh N, Eilati I, Kotler M. The association between adult attachment style \& mental health in extreme life-endangering conditions. Pers Individ Dif. 1999; 27: 831-42.

27. Berant E, Mikulincer M, Shaver P. Mothers' attachment style, their mental health, and their children's emotional vulnerabilities: a 7-year study of children with congenital heart disease. J Pers. 2008; 76(1): 31-66.

28. Bifulco A, Kwon J, Jacobs C, Moran PM, Bunn A, Beer N. Adult attachment style as mediator between childhood neglect/abuse and adult depression and anxiety. Soc Psychiatry Psychiatr Epidemiol. 2006; 41(10): 796-805.

29. Waller E, Scheidt CE, Hartman A. Attachment representation and illness behavior in Somatoform Disorders. J Nerv Ment Dis. 2004; 192(3): 200-9.

30. Riggs Sh A, Han G. Predictors of anxiety and depression in emerging Adulthood. J Adult Dev. 2009; 16: $39-52$.

31. Lipowski ZJ. Somatization: The concept and its clinical application. Am J Psychiatry. 1988; 145(11): 1358-68.

32. Crittenden PM. Attachment and psychopathology. Hillsdale, NJ: Analytic Pres. 1995; p. 367-406.

33. Sochos A, Tsalta A. Depressiogenic cognition and insecure attachment: A motivational hypothesis. IJP \& PT. 2008; 8(2): 157-70. 